\title{
Epigallocatechin-3-gallate inhibits bladder cancer cell invasion via suppression of NF-кB-mediated matrix metalloproteinase-9 expression
}

\author{
JIE QIN $^{1}$, YUNBIN WANG $^{2}$, YU BAI $^{3}$, KAI YANG $^{1}$, QIQI MAO ${ }^{1}$, YIWEI LIN $^{1}$, \\ DEBO KONG ${ }^{1}$, XIANGYI ZHENG ${ }^{1}$ and LIPING XIE ${ }^{1}$
}

${ }^{1}$ Department of Urology, First Affiliated Hospital, Zhejiang University School of Medicine, Hangzhou, Zhejiang 310003;
${ }^{2}$ Department of Urology, First Affiliated Hospital, Inner Mongolia Medical College, Hohhot,
Inner Mongolia Autonomous Region 010050; ${ }^{3}$ Department of Urology, Tumor Hospital of Yunnan,
Kunming, Yunnan 650118, P.R. China

Received April 13, 2012; Accepted August 21, 2012

DOI: $10.3892 / \mathrm{mmr} .2012 .1054$

\begin{abstract}
Bladder cancer is the fourth most common cancer in males and the ninth most common in females. However, despite the numerous advances made in the past few decades, the prognosis of patients with bladder cancer remains poor. Metastasis is one of the major causes of mortality in bladder cancer patients. Therefore, the inhibition of metastasis is one of the most significant issues in bladder cancer research. The present study was conducted to evaluate the anti-metastatic potential of (-)-epigallocatechin gallate (EGCG, the major phytochemical in green tea) against bladder cancer and its mechanism of action. EGCG efficiently and dose-dependently inhibited adhesion, migration and invasion of T24 human bladder cancer cells. Mechanistically, EGCG inhibited phosphatidylinositol 3'-kinase/Akt activation that resulted in inactivation of nuclear factor $-\kappa \mathrm{B}(\mathrm{NF}-\kappa \mathrm{B})$ and the inhibition of the expression of matrix metalloproteinase-9 (MMP-9), ultimately suppressing invasion and metastasis. These findings suggest that EGCG is a potential therapeutic candidate against tumor invasion.
\end{abstract}

\section{Introduction}

Bladder cancer, the fourth most common cancer in males and ninth most common in females, is a significant health problem. Despite the numerous advances made in the past few decades, the prognosis of patients with bladder cancer remains poor. Superficial bladder cancers have a high rate of tumor recur-

Correspondence to: Dr Liping Xie, Department of Urology, First Affiliated Hospital, Zhejiang University School of Medicine, Qingchun Road 79, Hangzhou, Zhejiang 310003, P.R. China E-mail: urology@yeah.net

Key words: bladder cancer, matrix metalloproteinase-9, epigallocatechin gallate, invasion, nuclear factor- $\mathrm{kB}$ rence and $10-30 \%$ of cases are likely to progress to invasive cancer (1). In addition, the results of treating patients who have advanced or metastatic bladder cancer are unsatisfactory in the majority of cases. Despite localized therapy with cystectomy and/or radical radiotherapy, the 5-year survival rate of patients with muscle-invasive transitional cell carcinoma is approximately $50 \%$ (2). Therefore, efforts are ongoing to explore novel mechanism-based targets and strategies for the management of bladder cancer.

Green tea, derived from the plant Camellia sinensis, is one of the most common beverages consumed worldwide, particularly in China. Epigallocatechin-3-gallate (EGCG) accounts for $50-80 \%$ of the catechins in green tea (3). Studies conducted on cell-culture systems and animal models as well as human epidemiological studies have shown that the polyphenols that are present in green tea may afford protection against a variety of cancer types, including bladder cancer $(4,5)$. However, the molecular mechanism underlying the invasion and migration effects of EGCG is not yet fully understood in bladder cancer.

Metastasis is one of the major causes of mortality in bladder cancer patients. Tumor invasion and metastasis are regarded as multistep phenomena that involve cell proliferation, proteolytic degradation of the basement membrane and extracellular matrix (ECM), altered cell adhesion, cell migration through the basement membranes to reach the circulatory system and the remigration and growth of tumors at metastatic sites (6). Components of the ECM are fundamental in the process of tumor invasion. Matrix metalloproteinases (MMPs) degrade the ECM, allowing urinary bladder transitional-cell carcinoma cells to spread and diffusely infiltrate the bladder parenchyma $(7,8)$. MMP-9 is postulated to play a critical role in tumor invasion. It has been reported that the expression of MMP-9 is regulated by nuclear factor- $\kappa \mathrm{B}$ $(\mathrm{NF}-\kappa \mathrm{B})$ since the MMP-9 promoter region contains DNA binding sites for $\mathrm{NF}-\kappa \mathrm{B}$.

The present study revealed that in human bladder carcinoma T24 cells, EGCG (a) inhibits the adhesion activities, cellular motility and invasional ability, (b) downregulates 
MMP-9 at the protein and mRNA levels and (c) inhibits $\mathrm{NF}-\kappa \mathrm{B}$ activation.

\section{Materials and methods}

Reagents. EGCG was obtained from Sigma (St. Louis, MO, USA). Primary antibodies to MMP-9, NF- $\kappa \mathrm{B}$ and $\beta$-actin and secondary antibodies were purchased from Santa-Cruz Biotechnology, Inc. (Santa Cruz, CA, USA). The bicinchoninic acid protein assay kit was obtained from Pierce Biotechnology (Rockford, IL, USA).

Cell culture. The human bladder cancer cell line T24 was obtained from the Shanghai Institute of Cell Biology, Chinese Academy of Sciences, Shanghai, China. The cells were cultured in RPMI-1640 medium supplemented with 10\% heat-inactivated fetal bovine serum, penicillin $(100 \mathrm{U} / \mathrm{ml})$ and streptomycin $(100 \mathrm{mg} / \mathrm{l})$ at $37^{\circ} \mathrm{C}$ in a humidified atmosphere containing 5\% $\mathrm{CO}_{2}$. EGCG was dissolved in PBS (pH 7.4) and used for the treatment of cells. The study was approved by the ethics committee of the First Affiliated Hospital, Zhejiang University School of Medicine, Hangzhou, China

Cell adhesion assay. For the cell-matrix adhesion assay $(9,10)$, 96-well plates were incubated with $100 \mu \mathrm{l}$ fibronectin $(10 \mu \mathrm{g} / \mathrm{ml})$ for $60 \mathrm{~min}$ and blocked with $1 \%$ bovine serum albumin at $37^{\circ} \mathrm{C}$ for $30 \mathrm{~min}$. The cells $\left(5 \times 10^{5} \mathrm{cells} / \mathrm{ml}\right)$ of $200 \mu \mathrm{l}$ were added to each well and incubated in EGCG (10-80 $\mu \mathrm{g} / \mathrm{ml})$ or vehicle alone for $90 \mathrm{~min}$ at $37^{\circ} \mathrm{C}$. After washing three times with PBS to remove nonadherent cells, $20 \mu \mathrm{l}$ MTT $(5 \mathrm{mg} / \mathrm{ml})$ was added to each well and incubated at $37^{\circ} \mathrm{C}$ for $4 \mathrm{~h}$. The plates were spun and the purple precipitates of formazan were dissolved in $150 \mu \mathrm{l}$ dimethyl sulfoxide. Absorbance was measured at $490 \mathrm{~nm}$ using an ELISA plate reader. The adhesion of cells treated with the vehicle was established as $100 \%$.

Cell migration assay. T24 motility was assessed using a wound closure assay (11). Approximately $1 \times 10^{5}$ T24 cells were cultured in 6-well plates. When the cells had grown to full confluence, a wound was induced on the monolayer cells by scraping a gap using a micropipette tip and removing any cell debris with PBS. The cells were then incubated in EGCG $(10-80 \mu \mathrm{g} / \mathrm{ml})$ or vehicle alone for $24 \mathrm{~h}$. Images were captured under x100 magnification using phase-contrast microscopy (Olympus IX70, Olympus, Tokyo, Japan) immediately or at 6, 12 and $24 \mathrm{~h}$ after wound incision. Image-Pro Plus 5.0 software (Media Cybernetics, Bethesda, MD, USA) was used to quantify the non-recovered wound area over the period of the experiment. The percentage of non-recovered wound area was calculated by dividing the non-recovered area by the initial wound area at zero time.

Cell invasion assay. The cell invasion assay was performed as previously described $(12,13)$. Briefly, T24 cells were plated at $5 \times 10^{6}$ cells $/ \mathrm{ml}$ in the upper compartment of a $8 \mu \mathrm{m}$-pore size Transwell migration chamber (Cat. no. 3422; Corning Inc., Corning, NY, USA) and cultured in medium containing EGCG $(10-80 \mu \mathrm{g} / \mathrm{ml})$ or vehicle alone for $24 \mathrm{~h}$. Cells were incubated for $24 \mathrm{~h}$ and those that did not migrate through the pores were removed by scraping the upper surface of the membrane with a cotton swab. Cells that had migrated to the lower surface of the membrane were fixed and stained. The cells that invaded through the insert were counted in 5 randomly selected microscopic fields (x400) per filter. The invasion of cells treated with the vehicle was established as $100 \%$.

Total RNA extraction and mRNA detection by reverse transcription-polymerase chain reaction $(R T-P C R)$. Total cellular RNA was extracted using the TRIzol reagent (Invitrogen, Carlsbad, CA, USA) following the manufacturer's instructions. RNA $(3 \mu \mathrm{g})$ was reverse transcribed using oligo(dT) primers and M-MLV Reverse Transcriptase (Promega, Madison, WI, USA). The resulting cDNA was amplified by PCR using gene-specific primers. The PCR primers for MMP-9 were 5'-CACTGTCCACCCCTCAGAGC-3' (sense) and 5'-GCCACTTGTCGGCGATAAGG-3' (antisense) and for GAPDH were 5'-ATGGCACCG TCAAGGCTGAG-3' (sense) and 5'-GCAGTGATGGCATGGACTGT-3' (antisense). PCR amplification consisted of an initial denaturation step $\left(95^{\circ} \mathrm{C}\right.$ for $3 \mathrm{~min}), 32$ cycles of denaturation $\left(94^{\circ} \mathrm{C}\right.$ for $\left.45 \mathrm{sec}\right)$, annealing $\left(57^{\circ} \mathrm{C}\right.$ for $\left.45 \mathrm{sec}\right)$ and extension $\left(72^{\circ} \mathrm{C}\right.$ for $\left.60 \mathrm{sec}\right)$ followed by a final incubation at $72^{\circ} \mathrm{C}$ for $10 \mathrm{~min}$. The PCR products were analyzed on $1.5 \%$ agarose gel. The gel was photographed and then quantitatively measured by scanning densitometry.

Western blot analysis. Western blot analysis was used to analyze the expression of various proteins as described previously (14). Briefly, cells were harvested at $24 \mathrm{~h}$ following EGCG treatment, washed with lysis buffer $(10 \mathrm{mmol} / 1 \mathrm{Tris}-\mathrm{HCl}, 0.25 \mathrm{~mol} / \mathrm{l}$ sucrose, $5 \mathrm{mmol} / \mathrm{l} \mathrm{EDTA}, 50 \mathrm{mmol} / \mathrm{l} \mathrm{NaCl}, 30 \mathrm{mmol} / 1$ sodium pyrophosphate, $50 \mathrm{mmol} / 1 \mathrm{NaF}, 1 \mathrm{mmol} / 1 \mathrm{Na}_{3} \mathrm{VO}_{4}, 1 \mathrm{mmol} / 1 \mathrm{PMSF}$, $\mathrm{pH}$ 7.5). Protein concentration in the resulting lysate was determined using the bicinchoninic acid protein assay. Appropriate amounts of protein (20-30 $\mu \mathrm{g}$ ) were resolved by electrophoresis in $10-15 \%$ tris-glycine polyacrylamide gels and transferred to nitrocellulose membranes. Membranes were blocked and then incubated overnight with the appropriate primary antibody at dilutions specified by the manufacturer. The membranes were then washed and incubated with the corresponding horseradish peroxidase-conjugated secondary antibody at 1:1,000 dilution in TBST. Bound secondary antibody was detected using an enhanced chemiluminescence (ECL) system (Pierce Biotechnology Inc.). To determine NF- $\kappa \mathrm{B}$ cellular localization, nuclear and cytoplasmic proteins were isolated from cells using a cell fractionation kit (Keygen, Nanjing, China). NF- $\kappa \mathrm{B}$ expression in the nuclear and cytoplasmic compartments was determined by immunoblot analysis.

Statistical analysis. All the experiments were performed in triplicate and performed a minimum of three times. All values are expressed as the mean \pm SD. Statistical significance was compared between various treatment groups and controls using the one-way analysis of variance (ANOVA). Data were considered to be statistically different when $\mathrm{P}<0.05$.

\section{Results}

EGCG inhibits T24 cell adhesion to fibronectin. Adhesive interactions between tumor cells and ECM proteins, including fibronectin, are deeply involved in a tumor 


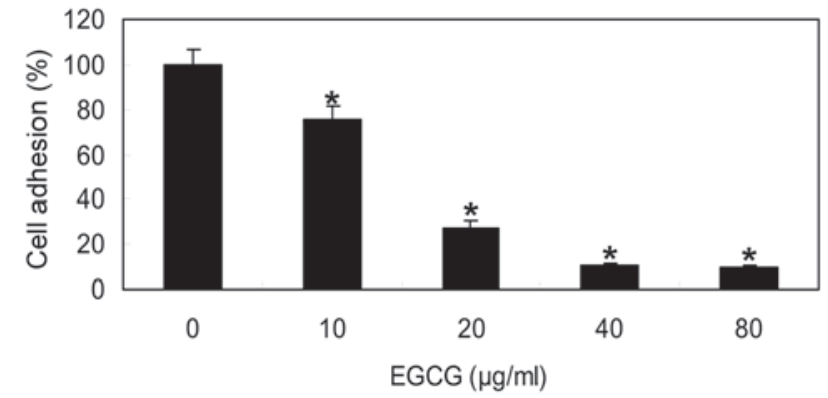

Figure 1. EGCG inhibits T24 cell adhesion to fibronectin. T24 cells were incubated with EGCG $(10-80 \mu \mathrm{g} / \mathrm{ml})$ for $1.5 \mathrm{~h}$ and adhesion to fibronectin was assessed. The proportion of adherent cells was counted as a percentage of the control. ${ }^{*} \mathrm{P}<0.05$. EGCG, (-)-epigallocatechin gallate.

growth, invasion and metastasis. Cell migration is intimately associated with cell adhesive properties. Thus the effects of EGCG on T24 cell adhesion were assessed. When the adhesion of T24 cells to wells coated with fibronectin in the presence of EGCG in solution was examined, it was revealed that EGCG inhibited cell adhesion to fibronectin dose-dependently (Fig. 1).

EGCG inhibits T24 cell migration. The ability of tumor cells to migrate has been associated with their metastatic potential and thus, the migration of EGCG-treated cells was investigated by the wound scratch assay. This assay is commonly used for testing the effects of pro- and anti-migratory agents on cultured cells. The migration of the cells into the wound area was assessed at time 0 and following the indicated hours. As shown in Fig. 2A, EGCG significantly inhibited the migration of T24 cells into the wounded area. In the wound scratch tests, the larger nonrecovered wound area may reveal that the anti-metastatic effect was more notable in these areas. Results demonstrated that at higher dosages of EGCG, the T24 cells spreading along the wound edges became slower than those treated with vehicle alone. The anti-metastatic effect of EGCG on T24 cells was thus confirmed to be dose-dependent (Fig. 2B).

EGCG inhibits T24 cell invasion. The in vitro cell invasion assay was based on the Boyden chamber assay. The Matrigel matrix served as a reconstituted basement membrane and the number of cells that migrated through the matrix was counted. The relevance of this assay for other invasion assays and for in vivo malignancy has been documented extensively. The invasion inhibition was determined following exposure to EGCG, as shown in Fig. 3. EGCG dose-dependently inhibited the invasion of T24 cells; at $80 \mu \mathrm{g} / \mathrm{ml}$ EGCG inhibited the invasion of $\mathrm{T} 24$ cells by $90 \%(\mathrm{P}<0.01)$. The results show that EGCG inhibited the invasion of highly metastatic human bladder carcinoma T24 cells in vitro.

EGCG downregulates MMP-9 at the protein and $m R N A$ levels in the T24 cell line. The effect of EGCG on the expression of MMP-9 was examined in order to study the possible anti-metastatic mechanisms of EGCG. An RT-PCR analysis was conducted to investigate the effect of EGCG on MMP-9 mRNA expression in T24 cells. As shown in Fig. 4A and B, electrophoresis scanning quantitative analysis indicated that
A

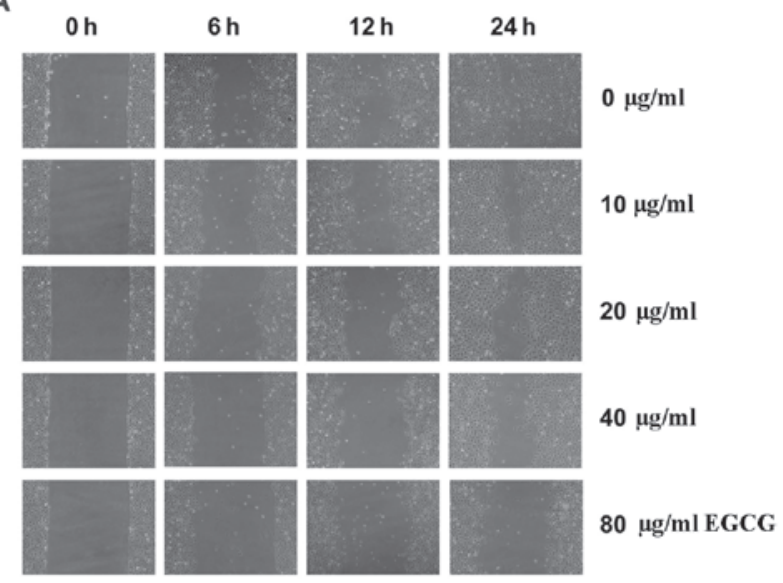

B

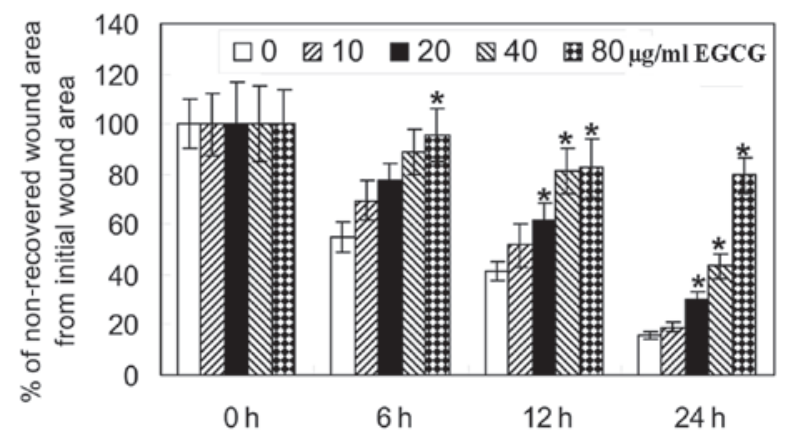

Figure 2. EGCG inhibits T24 cell migration. Wound was applied to cell monolayer in EGCG (10-80 $\mu \mathrm{g} / \mathrm{ml}$ ) or vehicle alone. (A) Representative fields showing the wounded area and cell migration into the wound at time 0 and after the indicated hours in the absence or presence of EGCG. (B) Bar graphs showing the percentage of non-recovered wound area from the intial wound area after 6,12 and $24 \mathrm{~h}$ of migration. ${ }^{*} \mathrm{P}<0.05$. EGCG, (-)-epigallocatechin gallate.

EGCG dose-dependently suppressed the MMP-9 mRNA in T24 cells. Western blot analysis was used to evaluate the protein expression of MMP-9 and the result was consistent with the changes of mRNA expression (Fig. 4C and D).

EGCG downregulates $N F-\kappa B$ in the $T 24$ cell line. $\mathrm{NF}-\kappa \mathrm{B}$ family members are pleiotropic transcription factors that control the expression of numerous genes involved in a variety of cellular responses, including those significant for cell invasion and metastasis, such as MMP-9. To further elucidate the effect of EGCG on NF- $\kappa \mathrm{B}$ activity, western blotting was applied to investigate the change of NF- $\kappa \mathrm{B}$ nuclear translocation in the T24 cells treated with various concentrations of EGCG. As shown in Fig. 4E, EGCG significantly inhibited $\mathrm{NF}-\kappa \mathrm{B}$ activation in T24 cells in a dose-dependent manner. This result suggests that $\mathrm{NF}-\kappa \mathrm{B}$ is likely to be involved in the inhibitory effect of EGCG on MMP-9 expression.

\section{Discussion}

In this study, the anti-metastatic potential of EGCG against bladder cancer and its mechanism of action was evaluated. 

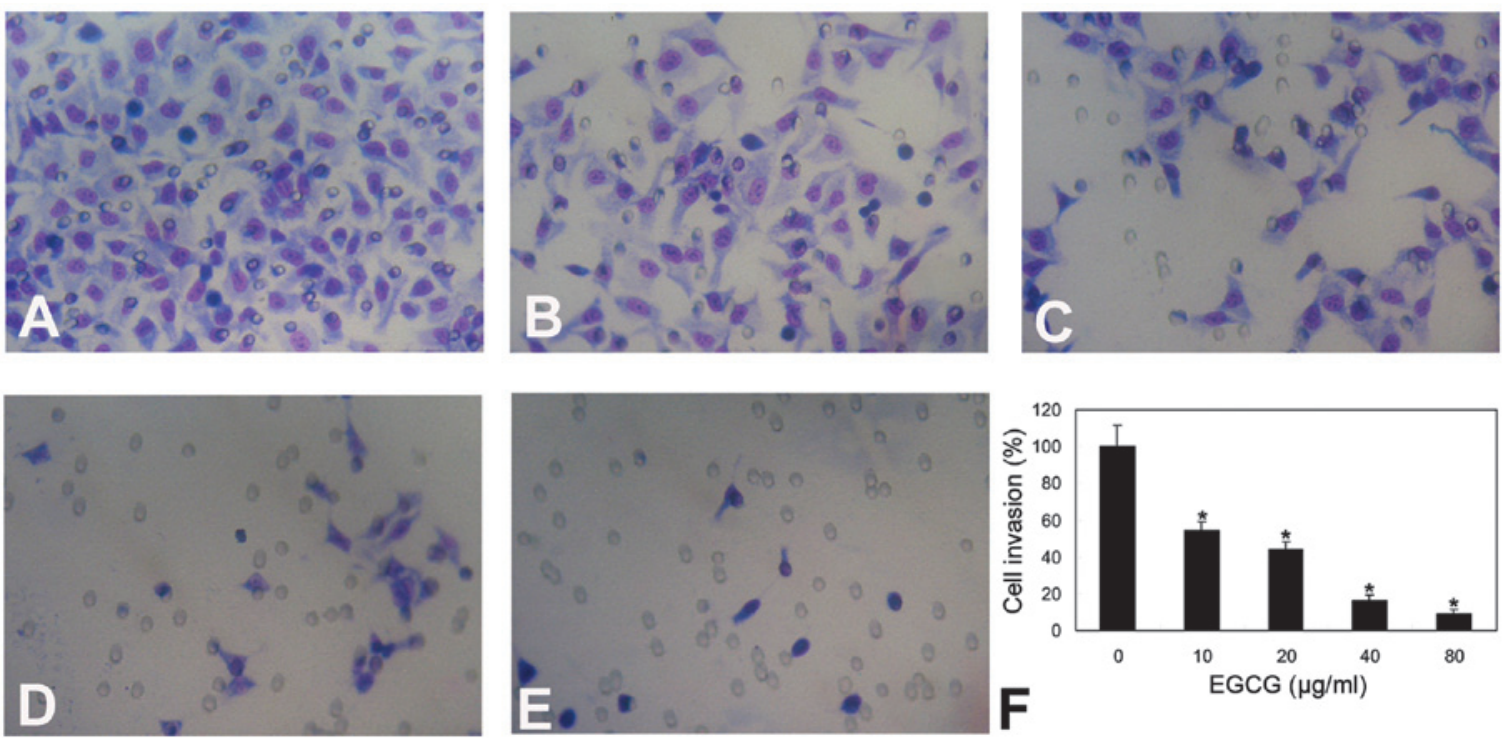

Figure 3. EGCG inhibits T24 cell invasion. Subconfluent T24 cells were trypsinzed, counted and resuspended in medium containing EGCG (10-80 $\mu \mathrm{g} / \mathrm{ml})$ or vehicle alone and transferred to the upper compartment of the Transwell migration chamber $\left(5 \times 10^{6} \mathrm{cell} / \mathrm{s} / \mathrm{ml}\right)$. (A-E) Representative fields showing the invaded cells that attached to the lower surface of the filter incubated with (A) vehicle alone or EGCG at (B) 10, (C) 20, (D) 40 and (E) $80 \mu \mathrm{g} / \mathrm{ml}$ for $24 \mathrm{~h}$ (x400). (F) Bar graphs showing the the proportion of invaded cells counted as a percentage of the control. ${ }^{*} \mathrm{P}<0.05$. EGCG, (-)-epigallocatechin gallate.

A

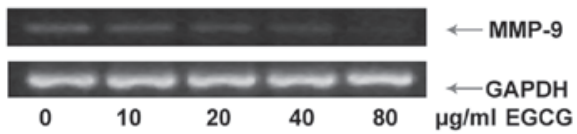

C

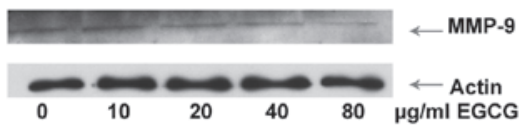

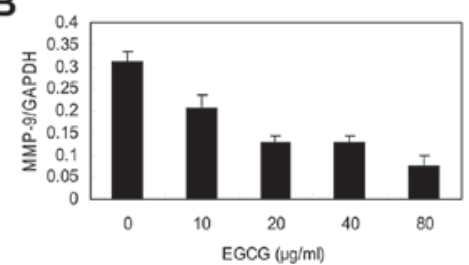

D

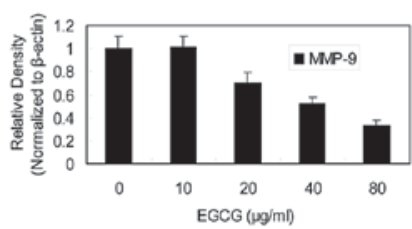

E

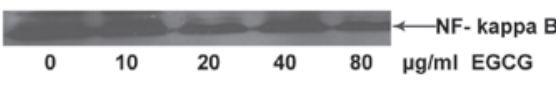

Figure 4. EGCG downregulates MMP-9 expression and inhibits NF- $\kappa$ B activation. Tumor cells were treated with various concentrations of EGCG for $24 \mathrm{~h}$. (A) The transcription of MMP-9 was determined by RT-PCR. (B) The ratio of MMP-9/GAPDH in the cells treated with various concentrations of EGCG by scanning densitometry. (C) The MMP-9 protein was determined by western blot analysis. (D) Protein expression levels of MMP-9 were normalized to that of actin and are presented as the fold change compared with controls. (E) NF- $\mathrm{B} / \mathrm{p} 65$ protein expression was assessed by immunoblot analysis in the nuclear fraction. MMP-9, matrix metalloproteinase-9; NF- $\kappa$ B, nuclear factor- $\kappa$ B; EGCG, (-)-epigallocatechin gallate; RT-PCR, reverse transcription-polymerase chain reaction.

Consistent with earlier observations, EGCG inhibited the invasion and metastatic potential of bladder cancer cells by the inactivation of $\mathrm{NF}-\kappa \mathrm{B}$ and then the inhibition of the expression of MMP-9.

Metastasis is a series of sequential steps, including cell proliferation, angiogenesis, cell adhesion, migration and invasion into the surrounding tissue. In the majority of cases, mortality from bladder cancer results from metastatic disease. Therefore, the inhibition of metastasis is one of the most significant issues in bladder cancer research. Numerous studies have reported that EGCG exerts its anticancer effects in various experimental systems. Using the T24 human bladder cancer cell line, previous studies (14) have demonstrated that EGCG treatment caused the dose- and time-dependent inhibition of cellular proliferation and viability and induced apoptosis. In addition to having chemopreventive activity,
EGCG has been shown to inhibit tumor invasion and angiogenesis, which are essential for the growth and metastasis of all solid tumors. Therefore, in this study, the effect of EGCG on the invasive ability of human bladder cancer T24 cells was investigated. It was revealed that EGCG efficiently and dosedependently inhibited the adhesion, migration and invasion of T24 cells.

The process of metastasis is promoted by expressing and secreting various proteolytic enzymes that degrade the majority of ECM components. MMPs are a family of zinc- and calcium-dependent endopeptidases, consisting of four subclasses based on substrate, including collagenases, gelatinases, stromelysins and membrane-associated MMPs. MMPs degrade ECM allowing urinary bladder transitionalcell carcinoma cells to spread and diffusely infiltrate the bladder parenchyma. To date, more than 20 human MMPs 
have been identified (15). MMP-9 is a key enzyme in tumor invasion for degrading type IV collagen, which is the major structural protein component in the ECM and basement membrane. Numerous studies have shown that MMP-9 is associated with invasiveness and bladder cancer progression. Therefore, in the current study, the effect of EGCG against MMP-9 expression was investigated. EGCG efficiently dose-dependently downregulated MMP-9 at the protein and mRNA levels in human bladder cancer T24 cells. The inhibitory effect of EGCG on MMP-9 may be partly responsible for its anti-metastatic potential.

It has been reported that the expression of MMP-9 is regulated by NF- $\mathrm{KB}$ since the MMP-9 promoter region contains the DNA binding sites of NF- $\kappa B$. NF- $\kappa B$ is typically a heterodimer consisting of $\mathrm{p} 65$ and $\mathrm{p} 50$ proteins. It is kept in an inactive form in the cytoplasm by inhibitory proteins called inhibitors of $\kappa \mathrm{B}$ (I $\kappa \mathrm{B})$. In response to an activation signal, NF- $\kappa \mathrm{B}$ is released from $I \kappa B$ and translocates from the cytoplasm to the nucleus. Following the translocation, in the nucleus, NF- $\kappa \mathrm{B}$ binds to the promoter region of MMP-9, leading to gene expression. To further elucidate the effect of EGCG on NF-кB expression, western blotting was applied to investigate the change of NF- $\kappa \mathrm{B}$ nuclear translocation in the T24 cells treated with various concentrations of EGCG. As shown in Fig. 4E, EGCG downregulated the expression of $\mathrm{p} 65$ protein in the nucleus, suggesting that $\mathrm{p} 65$ nuclear translocation was prevented by EGCG. This result suggests that NF- $\kappa \mathrm{B}$ is involved in the inhibitory effect of EGCG on MMP-9 expression.

The phosphatidylinositide-3 kinase (PI3K)/Akt signaling pathway is significant in regulating the expression of MMPs by transcriptional factors, including NF- $\mathrm{KB}$ (16-18). Metastasis is also regulated by the PI3K/Akt pathway, which has been implicated in a number of cellular functions, including cell survival, adhesion and metastasis. Accumulating evidence indicates a role for the PI3K pathway in the invasion of bladder cancer (19-21). Previous studies have shown that EGCG treatment resulted in a significant dose-dependent inhibition of constitutively elevated levels of phosphorylated PDK1 and phosphorylated (active) Akt (at Ser473 and Thr308) in T24 cells (14). The decrease in the expression of MMP-9 by EGCG was attributed to the inactivation of the PI3K/Akt signaling pathways and NF- $\kappa \mathrm{B}$ activity. This suppressive effect may contribute to the inhibition of invasion of T24 cells by EGCG.

In conclusion, the data from our study indicate that EGCG efficiently and dose-dependently inhibited the adhesion, migration and invasion of human bladder cancer T24 cells. This may be due to EGCG inhibition of PI3K/Akt, followed by the inactivation of NF- $\mathrm{KB}$ and then the inhibition of the expression of MMP-9 and ultimately suppressed the invasion and metastasis. The results of this study provide evidence that EGCG may be a potential therapeutic candidate against tumor invasion. Further studies on more detailed mechanisms and functions of EGCG are required.

\section{Acknowledgements}

This study was supported by grants from the National Natural Science Foundation of China (grant no. 30900552) and the Administration of Traditional Chinese Medicine of Zhejiang, China (grant no. 2009CA057).

\section{References}

1. Ashughyan VR, Marihart S and Djavan B: Chemopreventive trials in urologic cancer. Rev Urol 8: 8-13, 2006.

2. Pectasides D, Pectasides M and Nikolaou M: Adjuvant and neoadjuvant chemotherapy in muscle invasive bladder cancer: literature review. Eur Urol 48: 60-67; discussion 67-68, 2005

3. Khan N, Afaq F, Saleem M, Ahmad N and Mukhtar H: Targeting multiple signaling pathways by green tea polyphenol (-)-epigallo-catechin-3-gallate. Cancer Res 66: 2500-2505, 2006.

4. Yang CS, Maliakal P and Meng X: Inhibition of carcinogenesis by tea. Annu Rev Pharmacol Toxicol 42: 25-54, 2002.

5. Kemberling JK, Hampton JA, Keck RW, Gomez MA and Selman SH: Inhibition of bladder tumor growth by the green tea derivative epigallocatechin-3-gallate. J Urol 170: 773-776, 2003.

6. Liotta LA and Stetler-Stevenson WG: Tumor invasion and metastasis: an imbalance of positive and negative regulation. Cancer Res 51 (Suppl 18): 5054s-5059s, 1991.

7. Choi YD, Cho NH, Ahn HS, Cho KS, Cho SY and Yang WJ: Matrix metalloproteinase expression in the recurrence of superficial low grade bladder transitional cell carcinoma. J Urol 177: 1174-1178, 2007.

8. Di Carlo A, Terracciano D, Mariano A and Macchia V: Urinary gelatinase activities (matrix metalloproteinases 2 and 9) in human bladder tumors. Oncol Rep 15: 1321-1326, 2006.

9. Liu J, Zhang X, Yang F, Li T, Wei D and Ren Y: Antimetastatic effect of a lipophilic ascorbic acid derivative with antioxidation through inhibition of tumor invasion. Cancer Chemother Pharmacol 57: 584-590, 2006.

10. Suzuki Y and Isemura M: Inhibitory effect of epigallocatechin gallate on adhesion of murine melanoma cells to laminin. Cancer Lett 173: 15-20, 2001.

11. Hochman E, Castiel A, Jacob-Hirsch J, Amariglio N and Izraeli S: Molecular pathways regulating pro-migratory effects of Hedgehog signaling. J Biol Chem 281: 33860-33870, 2006.

12. Garbisa S, Biggin S, Cavallarin N, Sartor L, Benelli R and Albini A: Tumor invasion: molecular shears blunted by green tea. Nat Med 5: 1216, 1999.

13. Meng Q, Qi M, Chen DZ, et al: Suppression of breast cancer invasion and migration by indole-3-carbinol: associated with up-regulation of BRCA1 and E-cadherin/catenin complexes. J Mol Med (Berl) 78: 155-165, 2000.

14. Qin J, Xie LP, Zheng XY, et al: A component of green tea, (-)-epigallocatechin-3-gallate, promotes apoptosis in T24 human bladder cancer cells via modulation of the PI3K/Akt pathway and Bcl-2 family proteins. Biochem Biophys Res Commun 354: 852-857, 2007.

15. Overall CM and López-Otin C: Strategies for MMP inhibition in cancer: innovations for the post-trial era. Nat Rev Cancer 2: 657-672, 2002.

16. Chakraborti S, Mandal M, Das S, Mandal A and Chakraborti T: Regulation of matrix metalloproteinases: an overview. Mol Cell Biochem 253: 269-285, 2003.

17. Kim D, Kim S, Koh H, et al: Akt/PKB promotes cancer cell invasion via increased motility and metalloproteinase production. FASEB J 15: 1953-1962, 2001.

18. Rangaswami H, Bulbule A and Kundu GC: Nuclear factor-inducing kinase plays a crucial role in osteopontin-induced $\mathrm{MAPK} / \mathrm{I} \kappa \mathrm{B} \alpha$ kinase-dependent nuclear factor $\kappa \mathrm{B}$-mediated promatrix metalloproteinase-9 activation. J Biol Chem 279: 38921-38935, 2004.

19. Chiang GJ, Billmeyer BR, Canes D, et al: The src-family kinase inhibitor PP2 suppresses the in vitro invasive phenotype of bladder carcinoma cells via modulation of Akt. BJU Int 96: 416-422, 2005.

20. Rieger-Christ KM, Lee P, Zagha R, et al: Novel expression of $\mathrm{N}$-cadherin elicits in vitro bladder cell invasion via the Akt signaling pathway. Oncogene 23: 4745-4753, 2004.

21. Wu X, Obata T, Khan Q, Highshaw RA, De Vere White R and Sweeney C: The phosphatidylinositol-3 kinase pathway regulates bladder cancer cell invasion. BJU Int 93: 143-150, 2004. 